\section{THU0199 TOFACITINIB IMPROVES LEFT VENTRICULAR MASS AND CARDIAC OUTPUT IN PATIENTS WITH RHEUMATOID ARTHRITIS}

K. Kume, K. Amano, S. Yamada, T. Kanazawa, K. Hatta. Rheumatology, Hiroshima Clinic, Hiroshima, Japan

Background: Rheumatologists need to develop primary prevention strategies for cardiovascular disease (CVD) in rheumatoid arthritis (RA) patients. We reported tofacitinib (Tofa) improved arterial stiffness in RA patients. RA is associated with an increased left ventricular mass index (LVMI), a strong marker of cardiovascular mortality. There is no evidence that Tofa effects on left ventricular (LV) morphology and function.

Objectives: To study the effect of Tofa plus methotrexate (MTX) on LV morphology and function in MTX resistant active RA patients, in a cohort study design.

Methods: RA patients were eligible if they had active disease despite treatment with MTX. All patients have no steroids, and no previous history of CVD. Consecutive 28 patients with moderate to severe active RA patients (DAS28 > 3.2) despite MTX were received Tofa plus MTX. LV morphology and function was assessed with cardio-MRI at baseline and 24 weeks follow-up. Cardiovascular risk factors and clinical data were collected at regular visits.

Results: 24 patients completed 24 weeks. Left ventricular mass index (LVMI) was attenuated significantly by Tofa (week 0-week24, $-12.4 \pm 5.4 \mathrm{~g} / \mathrm{m}^{2} ; \mathrm{p}=0.0002$ ). Cardiac output (CO) was attenuated significantly by Tofa (week 0-week24, $0.87 \pm 1.2 \mathrm{l} / \mathrm{min}$ ). DAS28 and CRP improved significantly by Tofa (week 0 -week24; DAS28: $-2.26 \pm 0.91$; CRP: $14.1 \pm 8.7 \mathrm{mg} / \mathrm{l})(p<0.05)$. Surprisingly, the change of disease activity (DAS 28 and CRP) is no correlation with the change of LVMI or $\mathrm{CO}$ in this study. Observationally, 4 cases significantly improved right ventricular mass as well as left ventricular mass $(20 \%$ improved right ventricular mass index from baseline).

Conclusions: Tofa improved LVMI and CO in active RA despite MTX. TCZ improves LVMI and CO independently of its effects on disease activity. Tofa might be improved right ventricular mass. JAK-STAT pathway might be an important role of LV hypertrophy. Tofa, JAK-STAT pathway blocking, may prevent cardiovascular morbidity and mortality in RA.

\section{References:}

[1] Tocilizumab monotherapy reduces arterial stiffness as effectively as etanercept or adalimumab monotherapy in rheumatoid arthritis: an open-label randomized controlled trial. Kume K, et al.J Rheumatol. 2011 Oct;38(10):2169-71. doi: 10.3899/jrheum.110340. Epub 2011 Aug 1.PMID: 21807781

[2] Etanercept normalises left ventricular mass in patients with rheumatoid arthritis. Claire Immediato Daïen et al. Annals of the rheumatic diseases. 2013 Jun; 72(6); 881-7. doi: 10.1136/annrheumdis-2012-201489.

Acknowledgements: Thanks for Noriko Kuwaba to calculate data.

Disclosure of Interest: None declared

DOI: 10.1136/annrheumdis-2017-eular.1098

\section{THU0200 RISK FOR DEVELOPING ADVERSE EFFECTS CAUSED BY SALAZOSULFAPYRIDINE IN RHEUMATIC DISEASES}

\section{K. Nakanishi ${ }^{1}$, M. Kinjo ${ }^{2} .{ }^{1}$ Okinawa Hokubu Hospital, Nago; ${ }^{2}$ Okinawa CHUBU} Hospital, Uruma, Japan

Background: Salazosulfapyridine is non-antimicrobial sulfonamides, which is used as a synthetic disease modified anti-rheumatic-drug (DMARD) for rheumatoid arthritis and psoriatic arthritis. Prior study suggested sulfa allergy may be more commonly seen in patients with positive anti- Ro/SS-A antibody (anti-Ro).

Objectives: To identify the risk factor for adverse effects (AEs) caused by salazosulfapyridine in patients with rheumatic diseases.

Methods: We retrospectively identified patients $\geq 18$ years old who received salazosulfapyridine at a tertiary medical center in Japan between 2010-2015. Data were collected on the incidence of AEs, clinical features and autoantibodies.

Results: We identified 313 patients with rheumatic diseases who received salazosulfapyridine. Median age was 61 (range, 20-95); 215 of $313(67 \%$ ) were female (Table). The incidence of AEs was $15 \%$ (48/313); Median duration until developing AEs was 14 days (range, 2-50). AEs included rash (28), fever (19), elevated liver function tests (13), gastrointestinal symptoms (9), lymphadenitis (3), neutropenia and eosinophilia (1). Factors associated with AEs are female gender, positive anti-Ro or psoriatic arthritis. Multivariate logistic controlling for age, gender and anti-Ro showed that positive anti-Ro has 2.33 odds $(P=0.03$; $95 \% \mathrm{Cl}: 1.07-5.08)$ of having AE of salazosulfapyridine. Among patients without anti-Ro, subjects with psoriasis showed 9.95 odds $(\mathrm{P}<0.001 ; 95 \% \mathrm{Cl}: 3.51-28.2)$ of developing AEs than non-psoriatic patients.

Conclusions: AEs caused by salazosulfapyridine are common in patients with Table

\begin{tabular}{llll}
\hline Table & With AEs & Without AEs & \\
\hline & $(\mathrm{n}=48)$ & $(\mathrm{n}=265)$ & P value \\
\hline Age over 60 years - no. (\%) & $22(46)$ & $26(56)$ & 0.21 \\
\hline Female sex - no. (\%) & $42(88)$ & $173(65)$ & 0.002 \\
\hline Clinical diagnosis & & & \\
\hline Rheumatoid arthritis - no. (\%) & $26(54)$ & $214(81)$ & 0.002 \\
\hline Sjogren's syndrome - no. (\%) & $15(31)$ & $31(12)$ & 0.001 \\
\hline Psoriatic arthritis - no. (\%) & $19(40)$ & $11(4)$ & $<0.001$ \\
\hline Anti-Ro/SS-A antibody - no. (\%) & $14(29)$ & $28(11)$ & 0.006 \\
\hline
\end{tabular}

rheumatic diseases. Presence of anti- Ro or psoriasis may be a risk factor for AEs caused by salazosulfapyridine.

References:

[1] Suyama Y, Okada M, Rokutanda R, et al: Safety and efficacy of upfront graded administration of trimethoprim-sulfamethoxazole in systemic lupus erythematosus: A retrospective cohort study. Mod Rheumatol. 2016;26:55761.

[2] Maezawa R, Kurasawa K, Arai S, et al: Positivity for anti-RNP antibody is a risk factor for adverse effectscaused by trimethoprim-sulfamethoxazole, a prophylactic agent for $\mathrm{P}$. jiroveci pneumonia, in patients with connective tissue diseases. Mod Rheumatol. 2013;23:62-70.

Disclosure of Interest: None declared

DOI: 10.1136/annrheumdis-2017-eular.2409

\section{THU0201 OLDER AGE, HYPOALBUMINAEMIA AND RENAL FAILURE MIGHT BE POOR PROGNOSIS FACTORS FOR LOW DOSE METHOTREXATE-INDUCED MYELOSUPPRESSION IN PATIENTS WITH RHEUMATOID ARTHRITIS}

X.-N. Wei, D.-H. Zheng, Y.-Q. Mo, J.-D. Ma, Y.-L. Chen, L. Dai. Rheumatology, Sun Yat-Sen Memorial Hospital, Sun Yat-Sen University, Guangzhou, China

Background: Methotrexate (MTX) serves as an anchor drug in rheumatoid arthritis (RA) and the maximal dose of MTX from EULAR recommendation is 25$30 \mathrm{mg} / \mathrm{w}$. Small cases retrospective cohort studies reported that the mortality rate of RA patients with low dose (5-25 mg/w) MTX-induced myelosuppression was about $17-25 \%$. However, studies of low dose MTX-induced myelosuppression are rare in Chinese RA patients.

Objectives: To perform a retrospective case series analysis of the characteristics and outcomes of RA patients with low dose MTX-induced myelosuppression in China.

Methods: RA patients hospitalized at Sun Yat-Sen Memorial Hospital from January 2001 to December 2016 were recruited. Clinical data were collected and adverse effects were recorded simultaneously. Low dose MTX-induce myelosuppression was diagnosed as white blood cell $<4 \times 10^{9} / \mathrm{L}$ together with hemoglobin $<130 \mathrm{~g} / \mathrm{L}$ and platelet count $<130 \times 10^{9} / \mathrm{L}$ after treatment of MTX without an alternative cause for pancytopenia. Data were showed as mean \pm standard deviation Results: (1) There were 1137 RA patients recruited and 17 patients $(1.5 \%)$ of them were hospitalized for low dose MTX-induce myelosuppression. Among these 17 patients, $53 \%$ were females, age was $68 \pm 5$ years, disease duration was $12 \pm 11$ years.

(2) Four (23.5\%) patients had dose errors, taking MTX 5-10mg daily for 24 days (range: 5-80), MTX accumulated dose was 25-200mg before myelosuppression. Mean MTX dose in the other patients $(n=13,76.5 \%)$ was $11.0 \pm 1.7 \mathrm{mg} / \mathrm{w}$ (range: $7.5-15$ ), course of MTX was $10 \pm 11$ months (range: $0.5-48)$. Four (30.8\%) patients manifested myelosuppression within the first month after taking MTX and $4(30.8 \%)$ patients had been well on a stable drug dose (7.5-12.5) for more than one year before myelosuppression, 2 patients manifested myelosuppression after adding MTX dose to $15 \mathrm{mg} / \mathrm{w}$ for 2 months.

(3) Fifteen (88.2\%) patients had oral mucositis, eight of them had involvement of both oral mucosa and skin. Fever was noticed in $10(58.8 \%)$ patients. Infections were recorded in $6(35.3 \%)$ patients, manifested as pneumonia $(n=4)$, sepsis $(n=1)$, urinary tract infection $(n=1)$ and skin soft tissue abscesses $(n=1)$. Two patients experienced abdominal pain and melena.

(4) Among the patients with neutropenia $[\mathrm{n}=17$, mean neutrophil count: $(0.74 \pm 0.76) \times 10^{9} / \mathrm{L}$, range: $\left.0-1.83\right], 9(52.9 \%)$ developed severe neutropenia with neutrophil counts below $0.5 \times 10^{9} / \mathrm{L}$. Five patients developed severe thrombocytopenia (platelet count $<20 \times 10^{9} / \mathrm{L}$ ), and severe anemia occurred in 4 patients (hemoglobin $<65 \mathrm{~g} / \mathrm{L}$ ). Hypoalbuminemia $(30.0 \pm 2.8 \mathrm{~g} / \mathrm{L})$ was noted in all patients. Glomerular filtration rate $($ GFR $) \leq 30 \mathrm{ml} / \mathrm{min} / 1.73 \mathrm{~m}^{2}$ was noted in $4(23.5 \%)$ patients and GFR $\leq 50 \mathrm{ml} / \mathrm{min} / 1.73 \mathrm{~m}^{2}$ in $12(70.6 \%)$ patients.

(5) Pancytopenia recovered $(n=17)$ after discontinuation of MTX and supplementation of folic acid $(10-30 \mathrm{mg} / \mathrm{d})$. Only $3(17.6 \%)$ patients were treated with rescue intravenous leucovorin. Thirteen $(76.5 \%)$ were treated with granulocyte colony stimulating factor (G-CSF) and $7(41.2 \%)$ required blood products. Fifteen $(88.2 \%)$ required antibiotic therapy. Sixteen $(94.1 \%)$ patients was recovered and discharged, only one patient die from acute brainstem infarction but not from myelosuppression.

\begin{tabular}{|c|c|c|c|c|c|c|c|c|c|c|c|c|}
\hline Case & $\begin{array}{l}\text { Age } \\
\text { (v) }\end{array}$ & Sex & $\begin{array}{c}\text { Dose } \\
\text { (mg/w) }\end{array}$ & $\begin{array}{c}\text { Dose } \\
\text { errors }\end{array}$ & Fever & Mucositis & $\begin{array}{l}\text { Neutrophill count } \\
\left(\times 10^{9} /\right)\end{array}$ & $\begin{array}{l}\text { Platelet coun } \\
\left(\times 10^{\circ} \mathrm{L}\right)\end{array}$ & $\begin{array}{l}\text { Hemoglobir } \\
\text { (gL) }\end{array}$ & ${ }_{\left(\mathrm{m} / \mathrm{min} / .73 \mathrm{~m}^{2}\right)}^{\mathrm{Gr}}$ & Albumin & Outcome \\
\hline 1 & 74 & $\mathrm{~F}$ & 10 & + & - & + & 0.32 & 107 & 87 & 50.0 & 34.2 & Recovered \\
\hline 2 & 65 & M & 10 & + & + & + & 0.25 & 2 & 65 & 49.8 & 27.1 & Recovered \\
\hline 3 & 69 & M & 15 & + & + & + & 243 & 11 & 53 & 46.9 & 322 & Recovered \\
\hline 4 & 60 & M & 15 & + & + & + & 0.12 & 61 & 77 & 57.4 & 32.4 & Recovered \\
\hline 5 & 71 & M & 10 & . & + & . & 0 & 18 & 78 & 213 & 27.3 & Recovered \\
\hline 6 & 68 & F & 10 & & & + & 1.64 & 112 & 84 & 39.1 & 35 & Recovered \\
\hline 7 & 57 & F & 10 & . & + & + & 0.13 & 11 & 109 & 52.2 & 30.3 & Recovered \\
\hline 8 & 76 & M & 10 & : & + & + & 0.62 & 39 & 88 & 48.3 & 18.9 & Recovered \\
\hline 9 & 75 & F & 10 & . & . & + & 1.12 & 106 & 106 & 28.4 & 32.3 & Recovered \\
\hline 10 & 63 & F & 10 & . & + & + & 0.67 & 37 & 65 & 33.0 & 32.9 & Recovered \\
\hline 11 & 64 & F & 10 & . & + & + & 0 & 69 & 72 & 327 & 302 & Recovered \\
\hline 12 & 70 & $\mathrm{M}$ & 10 & . & . & + & 0.34 & 93 & 73 & 55.1 & 28.7 & Recovered \\
\hline 13 & 69 & $\mathrm{M}$ & 75 & & + & + & 183 & 112 & 83 & 47.0 & 348 & Recovered \\
\hline 14 & 62 & $\mathrm{~F}$ & 15 & & . & + & 0.28 & 124 & 53 & 23.3 & 31.2 & Recovered \\
\hline 15 & 80 & M & 12.5 & . & . & + & 1.05 & 49 & 70 & 42.4 & 28.8 & Recovered \\
\hline 16 & 74 & $\mathrm{~F}$ & 12.5 & & & & 1.75 & 106 & 74 & 618 & 28.6 & Recovered \\
\hline 17 & 57 & $F$ & 10 & . & + & + & 002 & 11 & 67 & 176 & 26 & Died \\
\hline
\end{tabular}


Conclusions: Older age, hypoalbuminaemia and renal failure might be poor prognosis factors for low dose MTX-induce myelosuppression in RA.

Disclosure of Interest: None declared

DOI: 10.1136/annrheumdis-2017-eular.3723

\section{THU0202 UNAFFORDABLE CONVENTIONAL AND ABSENT BIOLOGIC DMARDS: INCREASING THE BURDEN OF RHEUMATOID ARTHRITIS IN FYROM}

O. Gjeorgjieva, N. Memeti, L. Damjanovska-Krstikj. University Rheumatology Clinic, University Sts Cyril and Methodius, Skopje, Macedonia, The Former Yugoslav Republic Of

Background: In the developing world rheumatologists and their patients are struggling to implement treat to target therapy in established Rheumatoid Arthritis (RA)which means they can hardly establish remission and low disease activity which is the mainstay of the RA treatment. The main reason is the lack of conventional synthetic and biological (c and b) DMARDs in the therapeutic armamentarium as well as their high cost which increases already difficult burden of RA.

Objectives: The aim of the study is to evaluate the RA treatment and treatment expenses in a group of patients with established RA in FYR of Macedonia including the availability of DMARDs.

Methods: We have conducted a cross-sectional study at the University Rheumatology Clinic in Skopje, including 100 patients with established RA, who fulfilled RA classification criteria from 2010. Physical examination, laboratory analyses and DAS28 were performed and all patients filled a questionnaire with 13 questions about treatment expenses and availability.

Results: There were 82 females and 18 males, with mean age of 59 and disease duration of 8.3 (SD 7,3) years and moderate disease activity DAS28 3,9+/-1,47 and $75 \%$ of seropositive RA (double positive $30 \%$, Ant-CCP positive $30 \%$, RF positive $15 \%$ ) with mean CRP of $21,5 \mathrm{mg} / \mathrm{L}$ They spend from 10 to 100 Euros monthly (on average $27+/-17,6$ ) for the cs DMARDs therapy. Almost $80 \%$ think that the cs DMARDs therapy is too expensive for them and $100 \%$ of them could not afford to pay or co-pay for b DMARDs. Most of the patients (49\%) are using single cs DMARDs. Double and triple c DMARD therapy is used by $32 \%$ vs $17 \%$, respectively. Even though it is highly effective, patients consider triple cs DMARD therapy expensive and with very low compliance because of the high costs and low tolerability. Only $2 \%$ of the patiens are using b DMARDS using rituximab, the only available biologic DMARD therapy in FYROM. Around $70 \%$ are taking low dose prednisolone. Almost $50 \%$ of the patients cannot take the cs DMARD therapy with a prescription and have to buy their DMARDS without any coverage from the insurance fund and the same percent have problems to find the $\mathrm{c}$ DMARDs with prescription because it is not available. Almost half of the patients have heard about the $b$ DMARDs, most of them from their rheumatologist and $54 \%$ of them would like to receive it. The patient's reasons for taking b DMARDs are presented in Graph 1.

Conclusions: High expenses and low availability of c DMARDs on prescription and the urgent need for $b$ DMARDs are adding the burden of RA in developing countries including FYROM with the increased need for full coverage for conventional DMARDs and at least partial coverage of biologic DMARDs, especially anti-TNF agents by the insurance companies. The use of biosimilars might be highly appreciated in the future.

\section{References:}

[1] Aletaha D, Neogi T, Silman AJ et al. 2010 Rheumatoid arthritis classification criteria: An ACR/EULAR collaborative initiative. Arthritis Rheum 2010; 9 (62):2569-2581.

[2] O'Dell JR. Therapies for active rheumatoid arthritis after methotrexate failure N Engl J Med 2013; 369:307-318.

[3] Avci AB, Feist E, Burmester GR. Biologicals in rheumatoid arthritis current and future RMD Open 2015

Disclosure of Interest: None declared

DOI: 10.1136/annrheumdis-2017-eular.6485

\section{THU0203 CHANGES IN C-REACTIVE PROTEIN AND LIPID LEVELS IN PATIENTS WITH RHEUMATOID ARTHRITIS TREATED WITH ABT-494, A SELECTIVE JAK-1 INHIBITOR}

M. Nurmohamed $^{1}$, Y. Zhang ${ }^{2}$, J. Lin ${ }^{2}, \mathrm{H}$. Camp ${ }^{2} .{ }^{1}$ Amsterdam Rheumatology Immunology Ctr, VU Univ Medical Ctr, Amsterdam, Netherlands; ${ }^{2}$ AbbVie, $N$ Chicago, United States

Background: In patients (pts) with rheumatoid arthritis (RA) treated with ABT-494, dose-dependent increases in levels of low and high density lipoprotein cholesterol (LDL-C and HDL-C) were observed, along with decreases in levels of C-reactive Protein (CRP). Whether these changes are due to the control of inflammation or a direct effect on CRP production in the liver is not known.

Objectives: To explore the relationship between changes in HDL-C or LDL-C and CRP with ABT-494 treatment, and to assess whether the effect on lipids is dependent on improvement of RA signs and symptoms.

Methods: Data were from two phase $2 b$ controlled trials of ABT-494 in RA pts with inadequate response or intolerance to TNF inhibitors (TNF-IR, BALANCE-1) ${ }^{1}$, or with inadequate response to methotrexate (MTX-IR, BALANCE-2) ${ }^{2}$. Pts treated

with placebo or 3,6,12,18 mg ABT-494 twice daily for 12 weeks (wks) are included Levels of high sensitivity (hs) CRP, total cholesterol (TC), LDL-C and HDL-C were measured at baseline (BL) and $W k 2,4,6,8$ and 12. Atherogenic burden at $B L$ and Wk 12 was assessed by ratio of ApoB:ApoA1 and TC:HDL-C in 6 mg and 12 $\mathrm{mg}$ dose groups in both studies. Pearson's coefficients were calculated post hoc to assess possible correlations between HDL-C or LDL-C levels (or changes from $\mathrm{BL}$ ) with other variables including (high sensitivity) hsCRP, at BL and Wk 12. Pts were subgrouped by response: Sustained responders (SR), pts who achieved an ACR20 response at every visit from Wk 2-12; Responders (R), pts who achieved ACR20 at least once, but not at every visit; Non-responders (NR), pts who did not achieve ACR20 at any visit.

Results: The ratios of LDL-C:HDL- $\mathrm{C}^{1,2}$ and TC:HDL-C remained unchanged after 12 wks of treatment with ABT-494. The ratio of ApoB:ApoA1 also remained unchanged from BL to Wk 12: in BALANCE-1, 0.61 to 0.58 for the $6 \mathrm{mg}(\mathrm{n}=19)$, and 0.62 to 0.60 for $12 \mathrm{mg}(n=11)$ groups, and in BALANCE-2, 0.62 to 0.64 for the $6 \mathrm{mg}(\mathrm{n}=18)$ and 0.69 to 0.66 for $12 \mathrm{mg}(\mathrm{n}=16)$ groups. An inverse relationship between LDL-C or HDL-C and hsCRP was observed throughout the treatment period. At Wk 4, among the variables tested, the strongest correlation was observed between changes from BL in hsCRP and LDL-C $(-0.29, p<0.001)$ or HDL-C $(-0.26, p<0.001)$. Out of 420 pts, 104 pts $(25 \%)$ were ACR20 SR, 251 pts $(60 \%)$ were R and 65 pts (15\%) were NR. Compared to NR, SR and R had a greater absolute reduction in hsCRP (Fig. 1A). A robust percentage increase in HDL-C was observed in all 3 groups $(20.8 \%, 18.5 \%$ and $16.4 \%$ in SR, R and $N R$, respectively). Compared to the $S R$ and $R(14.6 \%$ and $16 \%$, respectively), a smaller percentage increase in LDL-C was observed in the NR (8.9\%) (Fig. 1B). Figure 1

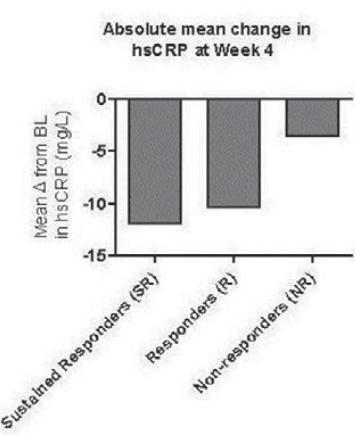

Conclusions: Atherogenic burden did not increase in pts treated with ABT-494 for 12 wks. Compared to non-responders, pts with a clinical response experienced a larger increase in lipids and a larger decrease in hsCRP. Limited data from these phase 2 studies suggest that there might not be an increased risk of cardiovascular events. Results from the larger phase 3 trials can provide more information. References:

[1] Kremer et al. 2016, Arthritis \& Rheum;68:2867

[2] Genovese et al. 2016, Arthritis \& Rheum;68:2857.

Acknowledgements: AbbVie: study sponsor, contributed to study design, data collection, analysis and interpretation; writing, reviewing, and approval of the final version. Medical writing: Naina Barretto, of AbbVie.

Disclosure of Interest: M. Nurmohamed Grant/research support from: Abbvie, Bristol-Myers Squibb, Merck Sharp \& Dohme, Novartis, Pfizer, Roche, Janssen, UCB and Sanofi., Consultant for: Abbvie, Bristol-Myers Squibb, Merck Sharp \& Dohme, Novartis, Pfizer, Roche, Janssen, UCB and Sanofi., Y. Zhang Employee of: AbbVie, J. Lin Employee of: AbbVie, H. Camp Employee of: AbbVie DOI: 10.1136/annrheumdis-2017-eular.2807

\section{THU0204 RELATIONSHIPS BETWEEN METHOTREXATE DOSAGES AND CLINICAL VARIABLES IN PATIENTS WITH RHEUMATOID ARTHRITIS WHO ACHIEVED REMISSION WITH METHOTREXATE MONOTHERAPY: A STUDY USING THE IORRA OBSERVATIONAL COHORT STUDY}

M. Tochihara ${ }^{1}$, Y. Katsumata ${ }^{1}$, E. Inoue ${ }^{1,2}$, Y. Kawaguchi ${ }^{1}$, E. Tanaka ${ }^{1}$, A. Nakajima ${ }^{1}$, K. Ikari ${ }^{1}$, A. Taniguchi ${ }^{1}, \mathrm{H}$. Yamanaka ${ }^{1} .{ }^{1}$ Institute of Rheumatology, Tokyo Women's Medical University; ${ }^{2}$ National Center for Child Health and Development, Tokyo, Japan

Background: Considerable variability exists in the way rheumatologists prescribe methotrexate (MTX) therapy in patients with rheumatoid arthritis (RA), including the dosage [ref.1]. Start higher doses or fast dose escalation are associated with higher efficacy, but also with more toxicity. In addition, factors such as renal function, body size, and age of the patient can affect the optimal dosage of MTX. Objectives: We aimed to study the relationships between MTX dosages and clinical variables in patients with RA who achieved remission with MTX monotherapy. 